\title{
Recomponiendo un puzle. Disquisiciones acerca de la restauración e interpretación de unas pinturas murales de estilo gótico lineal en la iglesia de Santa María la Nueva de Zamora
}

\author{
Sergio Pérez Martín, Marco Antonio Martín Bailón y Luciana Macedo Coelho \\ Proyecto Cultural Zamora Románica* y Ágora: Restauració d'Obres d'Art i Conjunts Artistics**
}

\begin{abstract}
Resumen: La iglesia de Santa María la Nueva de Zamora, de origen románico, se ha revelado como un puzle enigmático de difícil interpretación en su evolución constructiva. Dentro de un programa de intervenciones y estudios mucho más amplio, se exponen aquí los avances en su conocimiento surgidos con motivo de la restauración de las pinturas murales situadas en la sacristía sur, lugar especialmente sensible por ser la unión de varias fases del templo de los siglos XII, XIV y XVIII. Algunos de estos elementos -incluidas varias escenas del ciclo pictóricofueron tratados al descubrirse a mediados del siglo XX como piezas de un rompecabezas que debía rehacerse.
\end{abstract}

Palabras clave: Restauración, románico, pintura mural, gótico lineal, Zamora.

Refazer o puzzle. Considerações sobre o restauro e a interpretação de umas pinturas murais de estilo gótico na igreja de Santa Maria la Nueva de Zamora

Resumo: A igreja de Santa Maria A Nova de Zamora, de origem românica, tem-se revelado como um puzzle enigmático de difícil interpretação na sua evolução construtiva. Dentro de um programa de intervenções e estudos, muito mais amplo, são agora expostos os avanços sobre o seu conhecimento surgidos a propósito do restauro das pinturas murais situadas na sacristia sul, local especialmente sensível, por constituir a união de várias fases do templo nos séculos XII, XIV e XVIII. Alguns destes elementos - incluindo várias cenas do ciclo pictórico - foram tratadas ao descobrir-se, em meados do século XX, como peças de um puzzle que devia ser refeito.

Palavras-chave: Restauro, românico, pintura mural, gótico lineal, Zamora.

Remaking a puzzle. Considerations about the restoration and the interpretation of lineal gothic mural paintings at the church of Santa Maria la Nueva in Zamora

Abstract The church of Santa Maria la Nueva at Zamora, originally romanic, has emerged as an intriguing puzzle difficult to interpret in its constructive evolution. Within a program of interventions and much larger studies, advances are now presented in relation to the knowledge gained on the restoration of the wall paintings, located at the south sacristy. A sensitive place due the junction of several stages of the temple during XII, XIV and XVIII centuries. Some of these elements, including several scenes of the cycle of paintings, were treated after being found, in the mid-twentieth century, as a puzzle to be redone..

Key Words: Restoration, romanic, mural painting, lineal gothic, Zamora.

Quizá estemos obligados a una especie de eterno retorno, como al que condenó cruelmente Nietzsche al reflexivo Zaratustra. Tan sólo así podríamos percatarnos paulatinamente de la enorme cantidad de detalles que a diario pasan desapercibidos ante nuestros ojos. El hecho histórico tampoco debería por lo tanto permanecer ajeno a esa suerte revisionista. Al fin y al cabo, quienes tratamos de dedicarnos al mundo de la investigación histórica sabemos que esa necesaria vuelta nutre tantos y tantos trabajos y en no pocas ocasiones, planteado de manera rigurosa, hace avanzar decididamente a la ciencia histórica.

La aparición de nuevos documentos, el estudio de nuevas fuentes, los hallazgos motivados por excavaciones arqueológicas y cada día más las intervenciones restauradoras, nos obligan a una relectura de 
los monumentos, de sus orígenes o de su historia constructiva, en nuestro caso particular de las iglesias románicas de Zamora ${ }^{1}$. Sin embargo, menos son los casos en los que la información obtenida durante el proceso de conservación-restauración de un bien mueble se revela como un verdadero testamento vital de un edificio o al menos de una parte de él.

Bajo estos postulados se abordará precisamente uno de esos casos: las investigaciones y controversias surgidas durante la restauración de las pinturas murales de la capilla absidal sureste -actual sacristía- de la iglesia de Santa María la Nueva, parte integrante de un proyecto global que durante el año 2010 abordó la intervención sobre los tres ciclos pictóricos del templo, dos de ellos realizados durante el siglo XIV y un tercero mediando el XVI. Y quizá aquí -sin ser esta nuestra intención- algunos puedan ver un primer motivo de discusión, pues en efecto hemos considerado tales pinturas como un bien mueble, una vieja e imperecedera disputa a la que no permanecemos ajenos. Ś́, fueron concebidas como inmueble, y en su propio proceso de creación reside esa "inmovilidad", fueron pensadas para un lugar concreto y no otro, pero no menos cierto es que esos mismos axiomas pueden ser aplicados a las grandes máquinas retablísticas y su "movilidad" por unos u otros motivos (restauraciones, intervenciones arquitectónicas, cambios de gusto...) está lejos de toda duda, o incluso a una iglesia románica, a cuyos constructores resultaría desconcertante ver hoy su creación en un museo. La delgada línea que separa estos compartimentos estancos a veces resulta harto difusa. Lo que sí parece claro, y no por ello debe servir para desequilibrar la balanza, es que los profesionales encargados de su conservación-restauración son los mismos que lo hacen sobre otros bienes "móviles" hermanos, lienzos, tablas, e incluso las propias pinturas murales traspasadas a otros soportes, si bien, por su propia formación y tal como está organizada la enseñanza actualmente, tienen especialidades, y, en el caso de la pintura mural, se deben tener conocimiento de materiales inorgánicos y causas de deterioro específicos.

Sea como fuere, nuestra consideración en este momento se adhiere principalmente a otras motivaciones desgranadas en las próximas páginas y cuyo ilustrativo título algo avanza. La histórica recomposición -al menos parcialmente- de un pequeño puzle pictórico con motivo de una intervención restauradora de mediados del siglo XX constituye una pieza más del gran rompecabezas constructivo del edificio que lo alberga.

\section{A propósito de una omisión de la historiografía}

En efecto, el origen de este trabajo ha de rastrearse en una inexplicable omisión que la historiografía ha cometido, de manera intencionada o no, al acercarse al estudio e interpretación de estas pinturas. En su descargo diremos que el repertorio bibliográfico es aún escaso, principalmente porque el hallazgo de este ciclo pictórico tuvo lugar como veremos en 1949, fecha que, por otra parte, retrasa en algunos años la propuesta en el estudio más reciente sobre las mismas (Gutiérrez 2005: 358).

El primero en hacerse eco del impactante descubrimiento fue Victoriano Velasco en 1962, en la segunda edición de su Guía turística de la provincia de Zamora², revelando además que habían aparecido bajo copas (sic) de cal, indicio de que su hallazgo era aún un hecho reciente.

Hasta la década de los ochenta, serán los trabajos de carácter generalista los que recojan datos insustanciales al respecto y no exentos de errores, considerándolas como románicas, fechándolas en el siglo XIII o errando el momento de su hallazgo, si bien abrirán el camino hacia una primera aproximación a su temática ${ }^{3}$.

En 1988 se ponía de manifiesto la falta de un estudio riguroso sobre las pinturas medievales conservadas en la provincia zamorana denunciando la deuda de aquellos trabajos generales con las referencias recogidas por Gómez Moreno (Navarro 1988: 36-44) y sobre un panorama que desde comienzos de la centuria había cambiado ostensiblemente. Por primera vez se colocaba a las pinturas de Santa María la Nueva en su lugar, considerando el ciclo pictórico del ángulo suroeste de la nave como el grupo más estimable del estilo gótico lineal en la ciudad de Zamora y relacionable con la obra de Teresa Díez en el 
convento toresano de Santa Clara o con los maestros de la Catedral Vieja de Salamanca; y el grupo de la sacristía, al contrario de lo que se había pensado hasta el momento como el más tardío de los dos. A su parecer, éstas habrían de fecharse en la segunda mitad del siglo XIV y se deberían a un pintor de carácter más popular que imitó la estructura y algunas composiciones del ciclo pictórico de la nave, ya por entonces realizado. Al mismo tiempo se profundizaba en la temática de ambos conjuntos e incluso en la técnica empleada para su ejecución.

A comienzos de este siglo se publicaba una de las mejores aproximaciones al abanico provincial, sobre todo a nivel catalográfico (Grau 2001: 29-32)4. En ella se recogían nuevamente ambos conjuntos, si bien, su aportación más relevante incide en el problemático tema de la cronología, dando por buena la datación propuesta años atrás por Ramos de Castro, que las retrasaba a la segunda mitad del siglo XIII. Sin embargo yerra en la identificación de varias de las escenas reconocibles.

El último y más importante trabajo que recoge nuestras pinturas es una tesis doctoral acerca de la pintura de estilo gótico lineal en Castilla y León (Gutiérrez 2005), en ella leemos, sin duda, el estudio más completo realizado hasta el momento. Casi perfecto en la identificación iconográfica, a excepción de una de las escenas y otra inédita que quizá no pudo ver. Siguiendo la estela de Navarro retomará -creemos que acertadamente- la data trecentista, próxima, aunque posterior, al otro grupo de frescos situado en la nave del templo.

En este discurrir, la mayoría de los especialistas han reparado en el precario estado de las pinturas, en su hallazgo con motivo de un proyecto restaurador -a cargo de Luis Menéndez-Pidal y Francisco PonsSorolla-, incluso en su aparente aspecto inalterado, pues en aquella obra no parece que se interviniera más allá del picado de las capas de cal que las cubría y en su limpieza5. Sin embargo su detenido examen visual ofrece algunos datos e incógnitas en las que nadie parece haber reparado o que nadie se ha atrevido a plantear por falta de respuestas o porque hasta la fecha los estudios se han centrado exclusivamente en su análisis artístico e iconográfico, sin trascender a su contenedor, claramente alterado en distintos momentos, o a las patologías y deterioros que presenta su capa pictórica reveladoras de procesos constructivos con una innegable conciencia conservacionista y de valoración material, propia ya del siglo XX.

Como se tratará de poner de manifiesto en los siguientes capítulos, parece claro que parte de las pinturas fueron desmontadas y recolocadas posteriormente con motivo de la mencionada intervención. Cómo explicar si no que el hecho de que varios de los sillares del registro inferior estén asentados o recibidos con morteros de cemento Portland o similares. A qué se debe entonces la pérdida de la capa pictórica y mortero original en las juntas de unas zonas muy localizadas del conjunto. Indicios apreciables incluso en la propia fisonomía compositiva del muro, cuyos sillares se colocaron originalmente con una mínima carga de argamasa que difiere de la de los que afirmamos fueron extraídos.

\section{Deshaciendo el puzle: casi una arquitectura fingida}

Seguramente el estudio más certero sobre la interpretación de las distintas fases constructivas de la iglesia de Santa María la Nueva que se haya publicado sea el de la Enciclopedia del Románico (Nuño 2002: 411 425), con un profundo análisis estilístico y formal, con el que coincidimos en un alto porcentaje, aunque con algunos matices. En él, de manera decidida, se cuestionan algunos supuestos arrastrados desde la primera interpretación del Motín de la Trucha ${ }^{6}$ que ha instalado en el imaginario colectivo la idea de una iglesia de tres naves, con tres cabeceras y que una vez incendiada fue reconstruida por el pueblo llano, a lo que se deberían algunas de las impericias que claramente muestran su cabecera y capillas.

Debemos pues hacer un esfuerzo por eliminar todas las certezas y comenzar de nuevo, situándonos en la construcción de la torre a los pies de la iglesia, una gran mole pétrea, perfecta en su definición formal, madura y contemporánea en estilo de iglesias como Santiago del Burgo o la propia catedral, esto es segunda mitad del siglo XII. De aquí hacia atrás tenemos fases románicas a las que parece adosarse la torre 
Sergio Pérez Martín, Marco Antonio Martín Bailón y Luciana Macedo Coelho

Recomponiendo un puzle. Disquisiciones acerca de la restauración e interpretación de unas pinturas murales de estilo gótico lineal en la iglesia de Santa María la Nueva de Zamora

y la interpretación del citado Motín. Hacia delante, tenemos la construcción de los grandes arcos diafragma góticos, el arco toral, la elevación de los muros laterales de la nave y la cubrición de la misma con una techumbre de vigas madre y pares todos ellos policromados (a la que pertenecerían las vigas y piezas aparecidas en la intervención en las cubiertas en 20107). Es en este momento cuando se realizarían los ciclos pictóricos ahora restaurados. Ya en época moderna, tenemos reformas, la construcción del camarín y la redefinición formal de la cabecera mediado el siglo XX [figura 1].

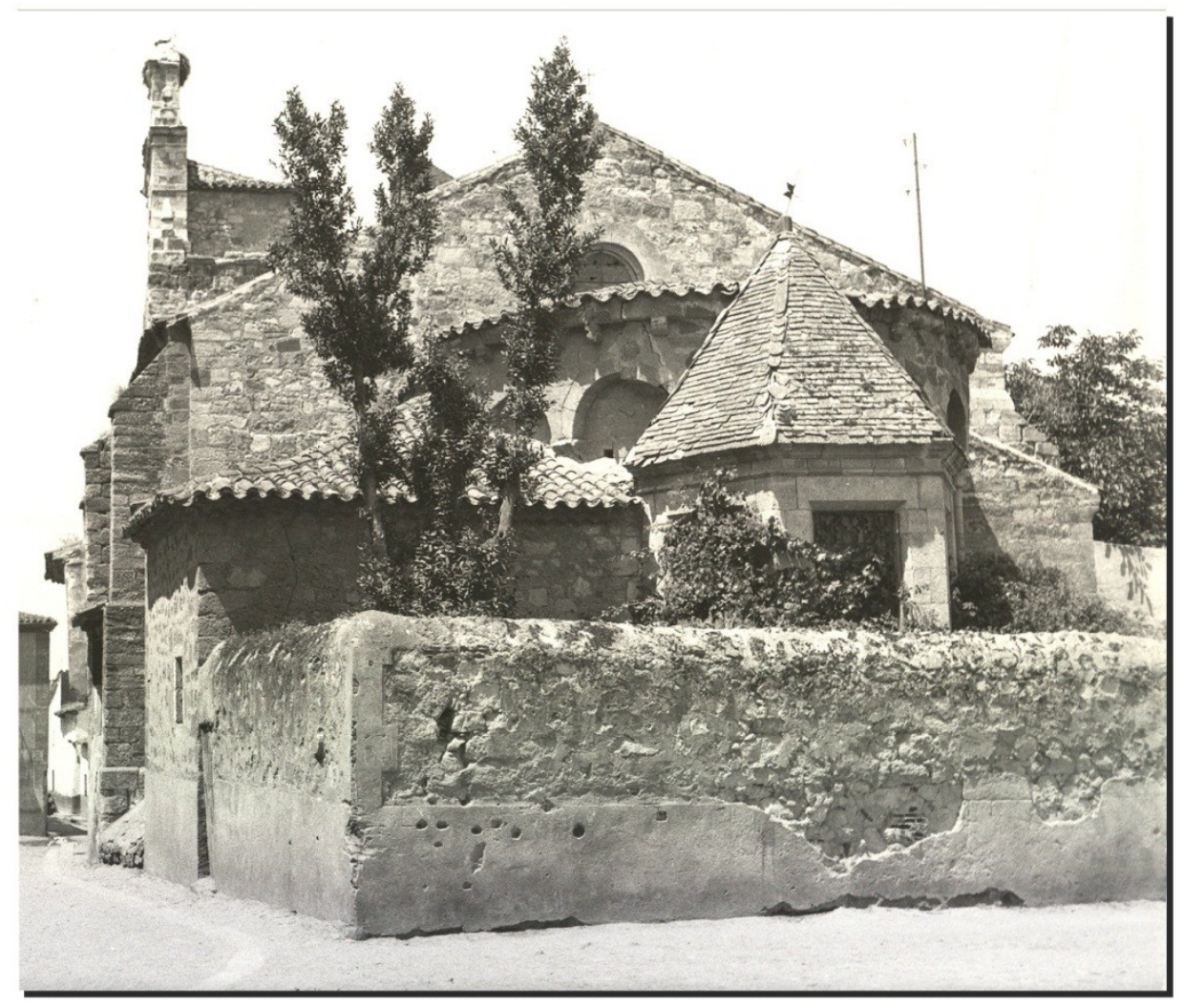

Figura 1. Iglesia de Santa María la Nueva con el camarín barroco, antes de la reforma de la cabecera. Fototeca Obispado ZamoraArchivo Gullón (Años 40).

Del complicado puzle que supone reconstruir los distintos momentos y etapas constructivas por las que ha pasado la iglesia de Santa María la Nueva son, por su posición, un excelente testigo las pinturas medievales en cuestión, y aquí nos centraremos en aportar alguna reflexión sobre el devenir de las mismas.

Ahora conocemos mucho más detalladamente las intervenciones llevadas a cabo por Menéndez-Pidal y Pons-Sorolla entre los años 1949 y $1958^{8}$ que incluyen la eliminación del camarín barroco, socalzo de muros, reparo de cubierta, solado y entorno. A ellos se debe la definición formal ideal que hoy podemos contemplar, pues reconstruyen la parte central del ábside y el hastial de la capilla sur o sacristía. Cuando los contemplamos, culpamos a aquella intervención de cualquier aspecto que nos resulta extraño o al menos no auténtico de algo que llamamos la primitiva iglesia. Pues bien, del mismo modo que hoy somos muy críticos con la eliminación de aquel camarín por ser un "inaceptable postizo", queremos destacar en este punto el excelente trabajo llevado cabo en la sacristía a pesar de que la documentación del mismo no fue todo lo ortodoxa que debería9.

En aquella primera intervención, como ya se ha dicho, se descubre la existencia de las pinturas y en las obras de 1951 se toman las medidas necesarias para la eliminación de todos los encalados sin perderlas o 
dañarlas ${ }^{10}$. Después de un minucioso análisis de estos documentos y del propio proceso de restauración ahora podemos avanzar la hipótesis, con las necesarias reservas, que ocurrieron más cosas en aquella intervención y que el orden de los sucesos quizás no es exactamente el registrado en la documentación administrativa. Mantenemos además, que todos los trabajos realizados en la misma tenían el objetivo claro e inequívoco de poner en valor las pinturas recién descubiertas, supeditando todas las decisiones a ese fin de mayor altura.

Comparando la planimetría de sendos proyectos [figura 2] y comprobando las hipótesis in situ podemos afirmar que la entrada a la sacristía se recompone en esta intervención llevando el marco de la puerta hacia la cara del presbiterio, para no interferir en la lectura de las pinturas. Esta operación obliga a desmontar los sillares por encima del arco, siendo recolocados después en su posición no tanto como aparejo sino más bien como si de una pieza de puzle se tratara (esto se aprecia muy bien en el mortero de cemento y cuñas de pizarra con que se asientan estas piezas y que no aparecen en el resto de las juntas, e incluso con la fisura muy moderna que aparece en la escena del Nacimiento, propia de un asiento diferencial en la descarga del arco).
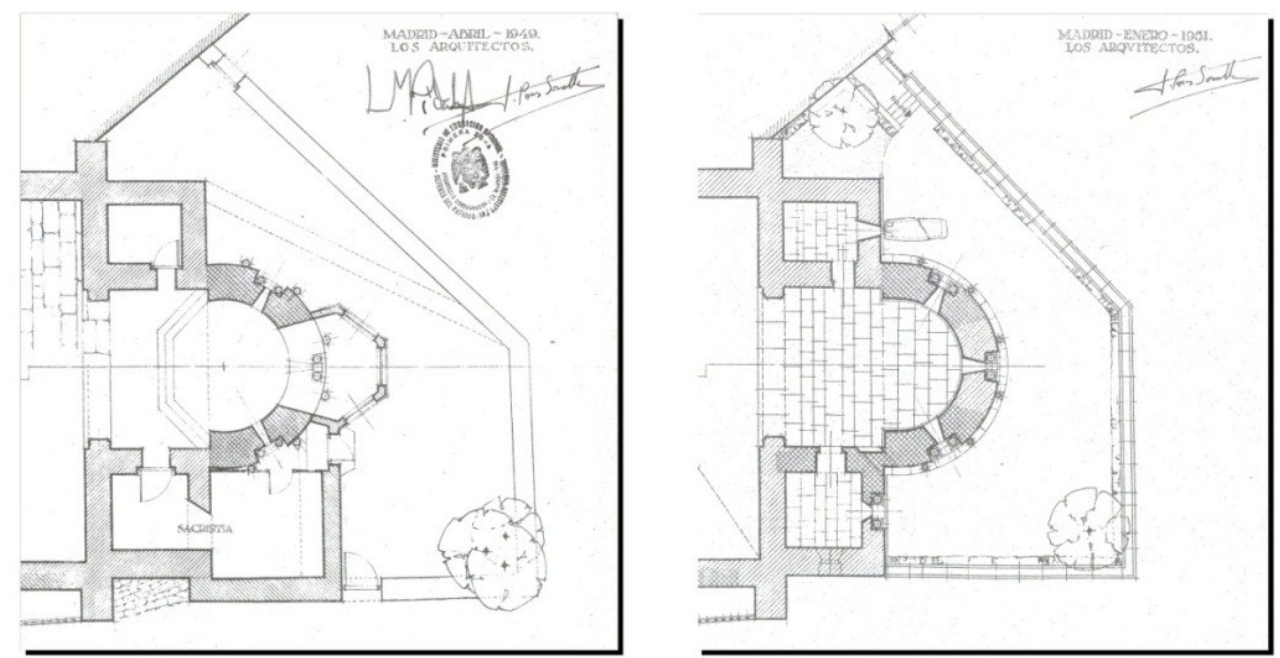

Figura 2. Comparativa planos Menéndez-Pidal y Pons-Sorolla (1949 y 1951), antes y después de la reforma de la cabecera. Ministerio de Cultura, AGA., (3)115 26/00295 y (3)115 26/00295.

Por otro lado, la representación gráfica del hastial que separaba la sacristía y la antesacristía, nos habla de un derrumbe o destrucción parcial de ese muro, sin borde definido. Esto también puede apreciarse en la planta, mucho más imprecisa, publicada por la Sociedad Castellana de Excursiones (García 1907: 103). En total se conservan dieciséis piezas primitivas, en el exterior: basa, columna, capitel y dos dovelas; y en el interior, con policromía: tres jambas de la ventana, cinco sillares y dos impostas taqueadas (y otra más descontextualizada en un arcosolio de la nave). La labra del hastial, las hiladas o el mortero, tanto de la cara interior como la exterior, parecen indicar que todo este muro es nuevo, apoyado en el ábside y desarrollándose hacia el sur. Se colocarán en su posición las piezas de mayor valor, con pintura o labra, pero mostrando especial cuidado en hacer coincidir las impostas y la iconografía en su lugar (la cara interior se hace coincidir con el final de la arquitectura fingida del ciclo). La traba desigual de este hastial con el muro sur, se explica fácilmente si primero reconstruimos este lienzo sin desmontar todavía la moderna sacristía, constituyendo un cerramiento de obra barato, impidiendo saqueos en la iglesia. En el último momento del proceso, antes de componer la cubierta, se tira este muro y se cierra la esquina, tomando ahora como hiladas dominantes las que vienen del muro sur y contrafuerte. 
Sergio Pérez Martín, Marco Antonio Martín Bailón y Luciana Macedo Coelho

Recomponiendo un puzle. Disquisiciones acerca de la restauración e interpretación de unas pinturas murales de estilo gótico lineal en la iglesia de Santa María la Nueva de Zamora

Aún más, la cara interior del muro oeste que impide la posible comunicación de este espacio con la nave como capilla lateral, se desmonta y se retrasa unos treinta y cinco centímetros de modo que queden al descubierto por completo los murales. En el arranque de la bóveda se aprecia perfectamente esta banda cuyo deterioro era menor al estar protegida por el espesor del muro y por tanto no afectada por los encalados sucesivos. Este extremo se ha podido comprobar con el análisis de la planimetría que revela ese ancho menor en este muro y que hace que parte del piñón de la nave repose sobre la bóveda de la sacristía [figura 3].

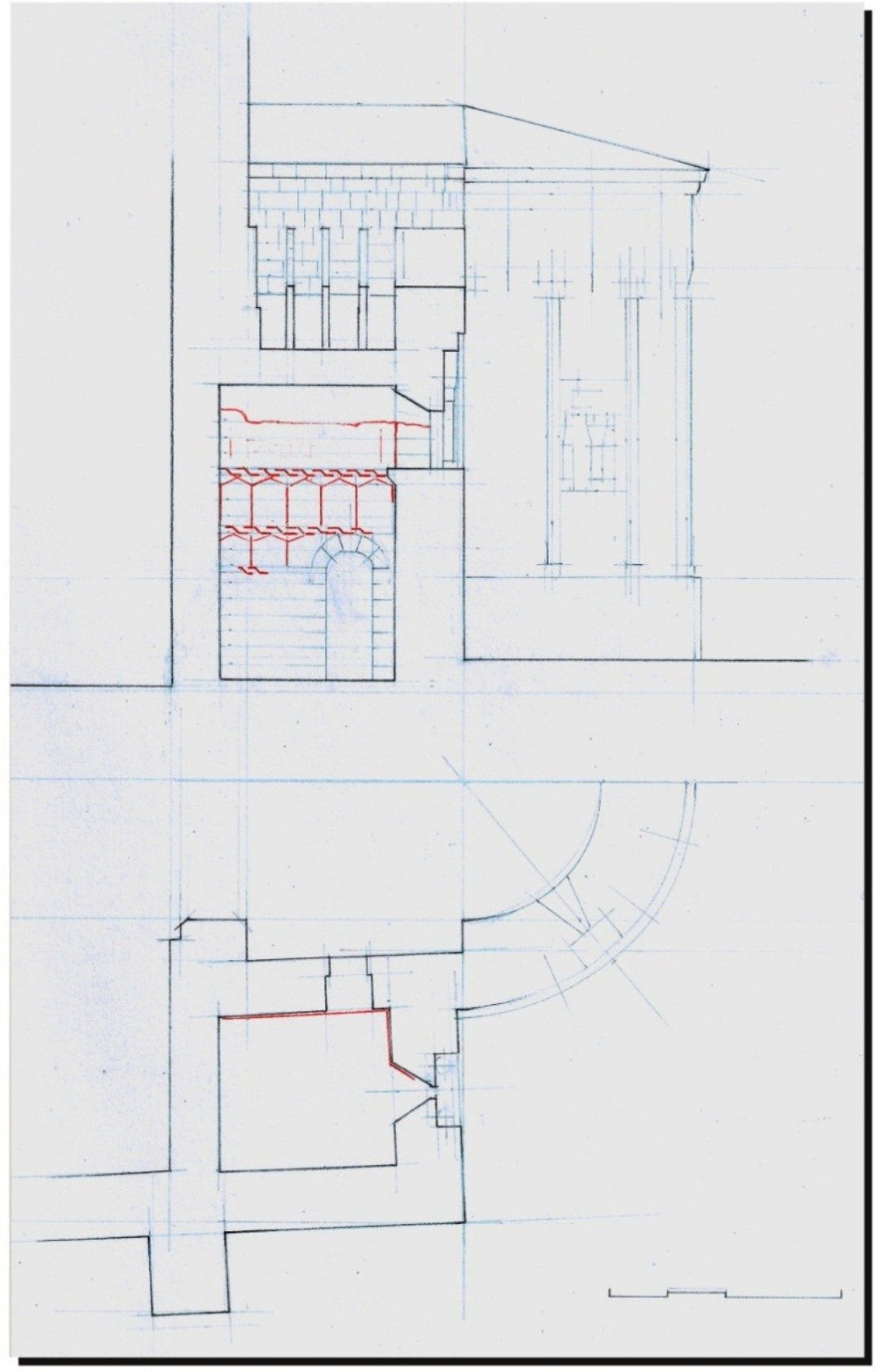

Figura 3. Análisis planimétrico donde puede observarse cómo la cara interior del muro Oeste de la capilla ha sido retrasado (APCZR). 
Así pues todos estos trabajos parecen responder a la idea general de sacar a la luz todo el ciclo pictórico descubierto, redefiniendo el límite oeste y quizás el este de la sacristía para contemplarlo por completo (al tratarse de escenas dentro de una arquitectura fingida se puede intuir los límites de la misma aunque no estuvieran visibles), y desmontando y volviendo a montar en su posición alguna de sus piezas siguiendo la iconografía. Todo esto debió hacerse pues, tras del minucioso desencalado y conocimiento del ciclo completo conservado, y por tanto las pinturas desencaladas en 1951 serían las de la nave, no así las de la sacristía, que tuvieron que ser necesariamente rescatadas en 1949 previo a la importante reforma de la misma.

Muchas otras dudas quedan aún sin embargo por resolver para poder completar el complicado rompecabezas constructivo. Tal es, por ejemplo, el repicado de las juntas de todo el conjunto, que hizo que nos planteáramos si en algún momento pudo estar desmontado por completo. O la aparición de restos de un llagueado antiguo tanto en la pintura como por encima de la bóveda, que parece indicar que ambos formaron parte del mismo espacio en algún momento y por tanto la bóveda estaría derruida. Y más complicado todavía resulta hablar de la reforma que pudo afectar al ábside y presbiterio en un momento anterior a la realización de las pinturas, pues ni el espesor del muro concuerda con la potencia del ábside, ni se explica la puerta cegada que daría directamente contra el hastial.

Ciertamente todo el ábside parece estar recompuesto en esos momentos previos a la realización de las pinturas. Así, las alturas de cornisas o ventanas no son coherentes en el conjunto del edificio, mostrándose demasiado altas. Ni hallamos pruebas fiables de las tres cabeceras románicas salvo en el relato del motín. Pero sobre todo, las ventanas supuestamente originales del ábside que sirvieron de modelo para la central en 1949, no presentan la sinceridad constructiva necesaria para considerarlas románicas: el abocinamiento, las jambas, los capiteles repicados... Parece más bien tratarse, de nuevo, de un puzle recompuesto con mayor o menor fortuna persiguiendo una imagen de conjunto, esta vez eso sí, en los albores del siglo XIII al XIV. La inminente excavación arqueológica interior y los exhaustivos estudios sobre los restos de la armadura mudéjar que se están realizando, permitirán al Proyecto Cultural seguir desvelando en próximas fechas los misterios que encierra este complicado rompecabezas.

\section{Desagravio al presunto homicida San José}

Tras el minucioso proceso de conservación-restauración lo primero que podemos decir -aparte obviamente de que se ha conseguido recuperar parte de su antiguo esplendor- es que nos encontramos en situación de hacer una lectura iconográfica definitiva del conjunto, subsanando los errores y lagunas dejados por quienes nos precedieron en su estudio.

De este incompleto ciclo pictórico dedicado a la vida de la Virgen y a la infancia de su Hijo restan diez escenas, repartidas aproximadamente en la mitad septentrional de la capilla, incluyendo su bóveda de cañón, si bien en este último ámbito se ubican dos grandes representaciones vinculables al ciclo de la Pasión. Así las cosas, las pinturas se encuentran repartidas en tres registros (mas el correspondiente a la bóveda), aunque uno de ellos ubicado en la zona más baja del paramento debemos considerarlo como tal con no pocas reservas [figura 4].

Cada uno de estos registros se separa por bandas de trenzado, incluido el superior que utiliza como soporte la imposta de billetes sobre la que arranca la bóveda; ornato visto en otros conjuntos pictóricos coetáneos, como el de Santa María del Castillo en Madrigal de las Altas Torres (Gutiérrez 2005: 97-99). Y cada uno de los capítulos se define por unos marcos arquitectónicos, organizados mediante arcos apuntados de intradós trilobulado, con arquitecturas por encima de sus arranques y rosetones polilobulados en sus enjutas. Igualmente es apreciable otra sutil separación entre cada uno de ellos, aunque en este caso a nivel cromático. Mientras el primer registro -bajo la imposta- presenta un fondo general de color rojizo, alternando fondos de escena negros y rojos; el segundo luce uno grisáceo, con fondos individuales que invierten el orden de colores. Mayor problema presenta el tercer registro, por su 
Sergio Pérez Martín, Marco Antonio Martín Bailón y Luciana Macedo Coelho

Recomponiendo un puzle. Disquisiciones acerca de la restauración e interpretación de unas pinturas murales de estilo gótico lineal en la iglesia de Santa María la Nueva de Zamora

prácticamente total pérdida, si bien podría intuirse próximo al primero, lo cual sería lógico para mantener la combinación polícroma.

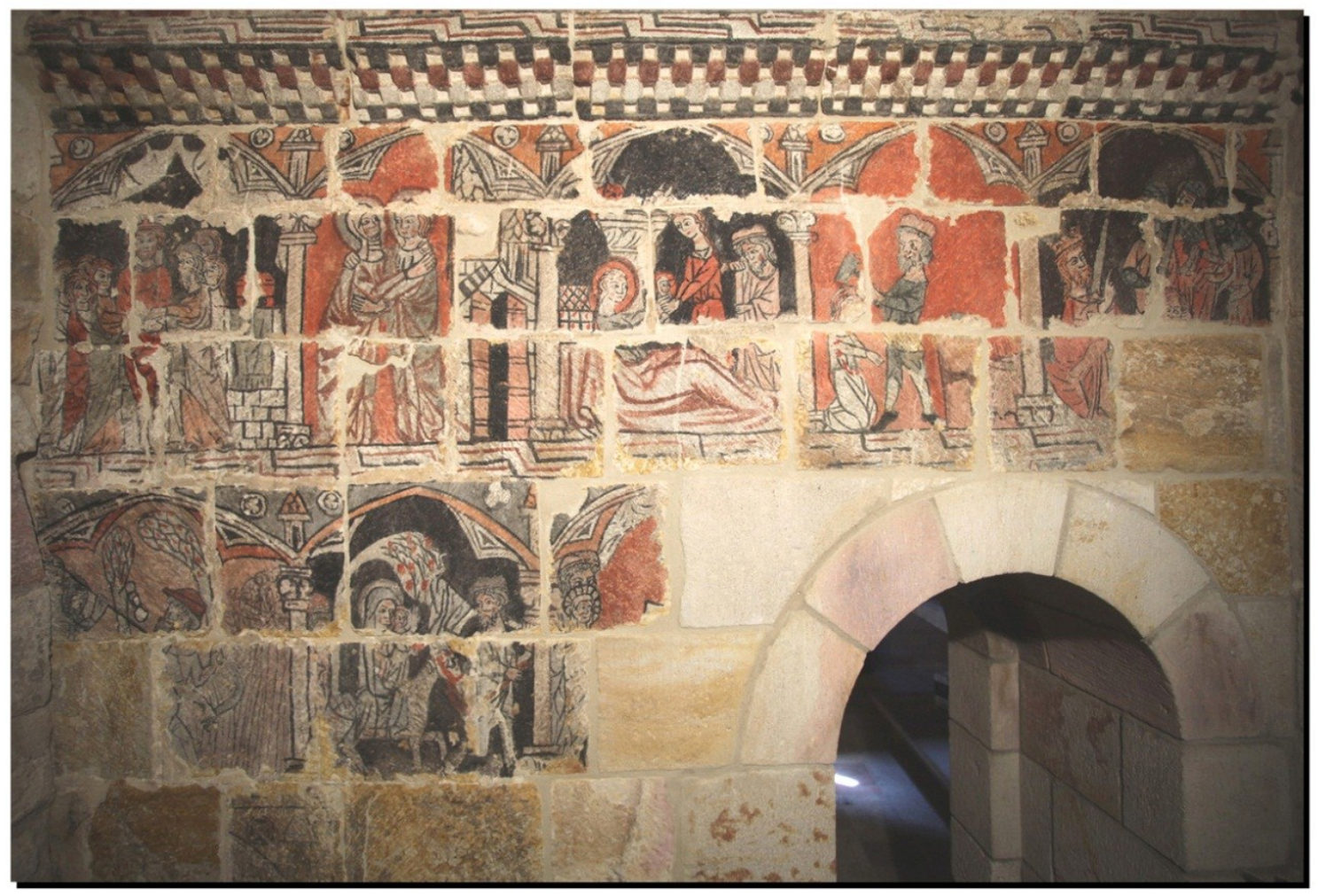

Figura 4. Vista general. Estado final (APCZR).

Como ya se ha apuntado, la lectura del programa iconográfico sigue el convencional orden de izquierda a derecha y de arriba a abajo, nuevamente exceptuando las representaciones pasionales, que tan sólo se atendrían a la primera norma, pues su importancia las otorga lugar y espacio preeminente. Su referencia a la literatura apócrifa ya fue puesta de manifiesto por Fernando Gutiérrez (2005: 356), si bien parece evidente que las principales fuentes utilizadas fueron el Protoevangelio de Santiago y el Evangelio del Pseudo Mateo.

La escena de los Desposorios de la Virgen ha sido una de las últimas en reconocerse (Rivera 2001: 149). Muestra en el centro al sumo sacerdote uniendo las manos de María y de José, gesto simbólico de la unión conyugal o conjunctio manuum, flanqueados de cinco figuras, aparentemente femeninas, quizá las cinco vírgenes -Rebeca, Séfora, Susana, Abigea y Zahel- que acompañarían y vivirían con María (Ps. Mt. VIII, 5). Los cortinajes, el altar y el pequeño arca, sitúan el episodio en el lugar sagrado, interior, detalle que difiere del común de las representaciones iconográficas (Réau 1996: 180).

Le siguen la Visitación, que hace especial hincapié en mostrar la diferencia de edad y de condición de ambas mujeres, pues mientras Isabel va cubierta con toca, María, doncella, iba en cabellos. Como se ha apuntado recientemente (Gutiérrez 2005: 356-357), a su derecha aparece una ciudad con las puertas abiertas, sin duda, una confusión iconográfica con el episodio del Abrazo ante la Puerta Dorada; y el Nacimiento, que al igual que el anterior, han sido identificados por todos los estudiosos. En él, tan sólo llamaremos la atención sobre la posición semitumbada de la Virgen, siguiendo la tradición bizantina, la presencia de una de las parteras ${ }^{11}$ y el "flotante" pesebre sobre el que pacen el buey y la mula. 
La escena siguiente ha debido provocar tal desconcierto a casi todos los que han escrito sobre estas pinturas que han preferido ignorar su existencia [figura 6]. Nuevamente el profesor Gutiérrez Baños (2005: 357) ha sido el pionero en sugerir una interpretación, aunque nosotros la descartaremos para proponer otra diferente. Permítannos hacer un desagravio al abnegado San José, pues aunque el tema resultaría verdaderamente interesante no parece que la pintura represente al Santo "matando a la partera". En efecto, la comadrona Salomé fue castigada por su incredulidad de la concepción virginal, viendo como se carbonizaban sus manos -luego recuperadas al tocar los pañales del Niño tras su arrepentimiento-, pero no parece que la esperase tan dramático final a manos del encolerizado padre. Analicemos, pues, la escena. Centra la composición un personaje barbado, de pelo largo, tocado con una especie de sombrero y vestido con camisa, calzas y medias- vestimenta que difiere de la que luce San José en el resto de representaciones; en sus manos porta un hacha, con la que asesta un golpe mortal en la cabeza a otro personaje, no necesariamente femenino -pues las pérdidas pictóricas impiden diferenciar el género-, vestido con túnica regada por la sangre y de rodillas; a su derecha una especie de altar, similar al que aparecía en la primera escena, aunque de menor tamaño. Sin embargo, la identificación de la escena se oculta en el relato apócrifo de Santiago (Pr. Ia. XXII-XXIV). Tras la Natividad y antes de la Matanza de los Inocentes, escena con la que continuará el ciclo pictórico, Herodes se había visto burlado por los Magos. Aquel montó en cólera y mando matar a todos los niños menores de dos años, entre ellos se encontraba Jesús, pero también su primo, San Juanito, que había sido ocultado en las montañas por su madre Isabel. En este trance los esbirros de Herodes habían ido ya en busca del pequeño y al no encontrarlo se dirigieron a su padre, Zacarías, que se hallaba en el templo, que alegó desconocer su paradero. El monarca, impacientado, le increpó "dinos la verdad de dónde está tu hijo, porque de lo contrario bien sabes que tu sangre está bajo mi mano" a lo que el sumo sacerdote respondio "seré mártir del Señor si te atreves a derramar mi sangre, porque mi alma será recogida por el Señor al ser segada una vida inocente en el vestíbulo del santuario". Según el relato, al romper el alba se produjo el asesinato, sin que los hijos de Israel se dieran cuenta del crimen, tanto es así que reunidos los sacerdotes y ante la tardanza del mártir, uno de ellos entró en el templo y vio al lado del altar su sangre coagulada, pero no su cuerpo que había desaparecido. Así, pues, nos parece aceptable que pueda tratarse de la representación del Martirio de San Zacarías, una rareza iconográfica, de escasísimos ejemplares conocidos $^{12}$.

Cierra el registro superior la Matanza de los Inocentes, de difícil reconocimiento para algunos (Ramos 1977: 429 y Grau 2001: 29), aunque a simple vista bastante clara ante la presencia de un Herodes justiciero acompañado por sus soldados ejecutando a los infantes y una mujer que parece mesarse los cabellos en señal de duelo (Gutiérrez 2005: 357). El relato prosigue en la banda intermedia con el Milagro del Trigo, episodio acaecido durante la Huida a Egipto, y cuyo origen se ha buscado en otro de los apócrifos que gozó de notable fortuna, el Liber de infantia Salvatoris, escrito en el siglo XIII. En él, y de manera muy resumida, se narraba el encuentro con un antipático labrador al que Jesús castiga arruinándole la cosecha. En contraposición, la tradición oral habría añadido otro episodio, protagonizado por María, en el que un labrador amable es recompensado con una gran cosecha que crecerá de la noche a la mañana y que confunde y hace desistir a los perseguidores al oír que la Sagrada Familia pasó por allí en el momento de la siembra ${ }^{13}$. Precisamente en actitud de siega, aparece el campesino, mientras es acosado por los soldados.

La Huida a Egipto, propiamente, queda efigiada con el popular Milagro de la palmera, extraído del Evangelio del Pseudo Mateo y matizado poéticamente por la Leyenda Dorada. El texto apócrifo cuenta como al tercer día de viaje, María se sintió fatigada por el calor del sol y viendo una palmera pidió a José le permitiera descansar bajo su sombra. Más tarde, mirando la copa del árbol, y viéndola llena de frutos pidió a su esposo que cortara algunos dátiles para ella. Ante la dificultad, por su altura, el Niño Jesús dijo a la palmera "agáchate árbol y con tus frutos da algún refrigerio a mi madre" y la palmera inclino su copa hasta permitirles cortar todos los dátiles que necesitaba. En su discurrir, a lomos de un jumento, varios personajes hacían el camino con ellos, aquí representados en el extremo izquierdo de la composición, según los textos Santiago el menor o los cuatro hijos de José y la partera Salomé (Réau 1996: 285). 
Sergio Pérez Martín, Marco Antonio Martín Bailón y Luciana Macedo Coelho

Recomponiendo un puzle. Disquisiciones acerca de la restauración e interpretación de unas pinturas murales de estilo gótico lineal en la iglesia de Santa María la Nueva de Zamora

La última escena se encuentra parcialmente perdida y más allá de algunas interpretaciones francamente desencaminadas, estamos de acuerdo con Fernando Gutiérrez (2005: 357) que lo vincula con episodios de la Sagrada Familia en Egipto, sin embargo tampoco podemos descartar que se trate de algún tema como la Presentación, cronológicamente anterior, aunque muy frecuente en estos ciclos pictóricos. Las dos personas situadas a la izquierda, quizá María y José, parecen asistir atentamente al asunto que ocurriese en el centro de la pintura. Mucho menos resta del tercer registro, tan sólo un sillar con restos polícromos sin temática reconocible.
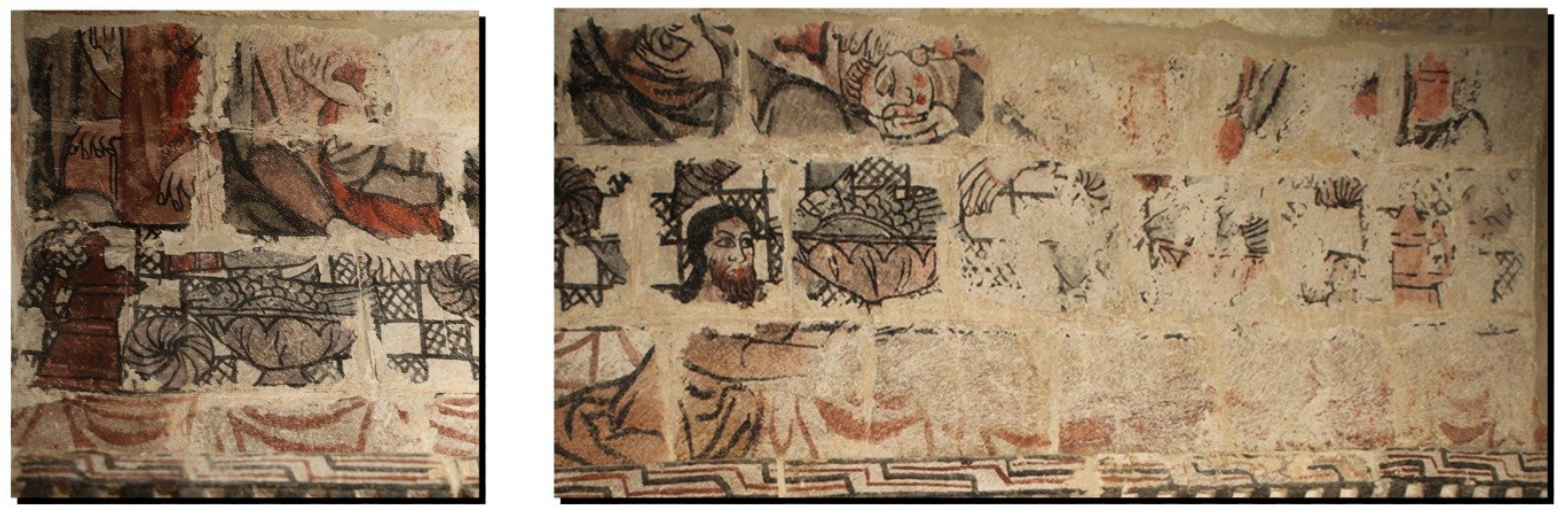

Figura 5. Detalles Última Cena. Estado final (APCZR).

Finalmente en la bóveda, ocupando toda su anchura se conserva la mitad inferior de una representación de la Última Cena [figura 5]. La mesa puesta y aderezada y los comensales dispuestos a su alrededor, tan sólo reconocibles Judas, en primer término y por delante de la mesa que sustrae un pescado de una de las fuentes; y el discípulo amado, que reposa su cabeza en el regazo de Cristo. Y en el muro este, en el abocinamiento de la ventana, unos escasos restos hasta ahora sin interpretación. Ahora podemos desvelar que se trata de uno de los momentos anteriores a la Cena, concretamente el episodio del Lavatorio de los pies. Jesús, situado a la derecha, de hinojos, y con una especie de toalla ceñida a la cintura, lava los pies seguramente- de Pedro, mientras otros apóstoles en pie y situados detrás, esperan su turno [figura 8].
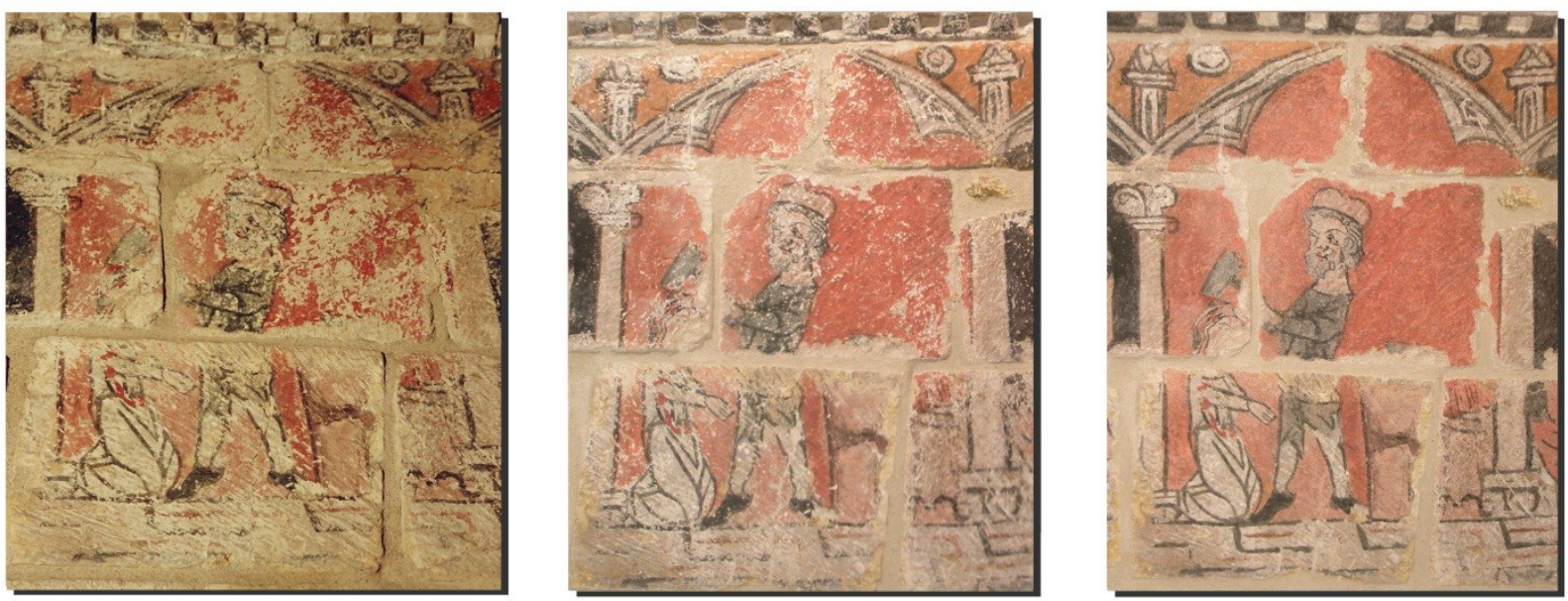

Figura 6. Martirio de San Zacarías. Proceso de trabajo (APCZR y Ágora). 
Sergio Pérez Martín, Marco Antonio Martín Bailón y Luciana Macedo Coelho

Recomponiendo un puzle. Disquisiciones acerca de la restauración e interpretación de unas pinturas murales de estilo gótico lineal en la iglesia de Santa María la Nueva de Zamora

\section{Conservar, restaurar, redescubrir}

Las pinturas presentaban un estado de conservación precario debido a las diversas transformaciones arquitectónicas, agresiones sufridas por el uso del espacio, de las degradaciones intrínsecas debido al propio envejecimiento de los materiales dejando visible unas patologías fruto del paso del tiempo, tales como: la falta de cohesión del soporte de sillería de piedra como también de los pigmentos, provocando en parte, la pérdida de capa pictórica afectando y debilitando directamente algunas zonas pigmentadas. Por todo ello, se ha considerado la necesidad de realizar una intervención de conservación-restauración de las pinturas para garantizar su conservación y devolver al público la posibilidad del disfrute de las policromías que se cobijan en esta capilla.

Dichas causas externas (reforma arquitectónica, encalados, repicados, introducción de materiales no afines a la obra), a las que se han visto expuestas a lo largo de todos estos años, han afectado negativamente a la policromía, por lechadas sobrepuestas de cemento Portland que han ocasionando una alteración en la percepción visual original de estas pinturas y también la piedra al ser substituidos los rejuntados de cal originales por otros a base de cemento Portland. En intervenciones anteriores, también se han utilizado arcillas y adobes con restos de paja para los rellenos de distintas oquedades del muro, las cuales se sobreponen y ocultan parte de la policromía original. Todo ello ha generado una acusada alteración en la percepción del aspecto original del conjunto, pero sobretodo una degradación de las distintas capas que conforman esta pintura: soporte de piedra, capa fina de enlucido y capa pictórica.

Otras degradaciones como las diversas lagunas, grietas, rasguños y golpes que presentan las pinturas se deben a los ataques vandálicos y al uso del espacio de la Capilla como Sacristía.

Debido a las patologías descritas y a las múltiples agresiones ya mencionadas, se observa una importante pérdida de la capa pictórica, dificultando la legibilidad iconográfica de las pinturas, muy enfatizada en la parte superior derecha junto al abocinamiento de la ventana, donde prácticamente solo se perciben pequeños restos esparcidos de policromía.[figura 7].

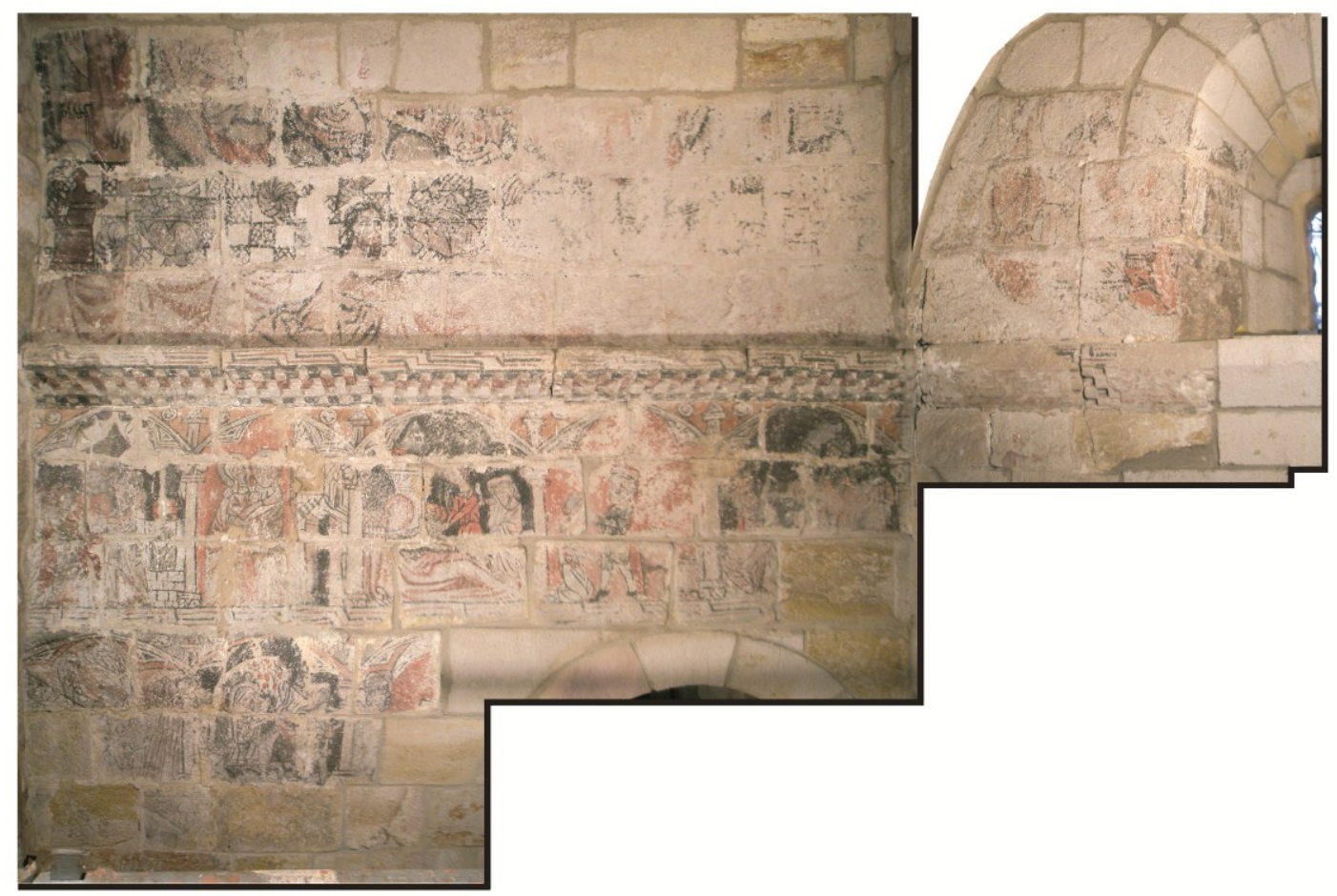

Figura 7. Desplegado del conjunto pictórico. Estado inicial (Ágora). 
Como soporte nos encontramos con un muro de piedra labrada rejuntada con mortero de cal, denotando una textura rugosa que se transfiere a las capas superiores: capa fina de enlucido y la capa pictórica.

El enlucido aplicado sobre la sillería de piedra es muy fino y muy pobre hasta tal punto que en gran parte del conjunto pictórico no existe, porque no se ha aplicado de forma homogénea y en su defecto, la capa pictórica la encontramos aplicada directamente sobre la piedra.

La técnica utilizada, pintura al temple ejecutada con tintas planas, con tonos muy definidos, colores opacos e intensos contorneados por líneas negras. Podemos apreciar que las gamas dominantes son colores de diferentes tonalidades en rojos, negros, pardos, verdes oscuros y blancos-grisáceos. Las pinceladas definen una ejecución rápida y espontánea, pudiéndose observar goterones muy visibles, sobretodo, en los trazos de las líneas negras. A luz rasante se observa cierta rugosidad debida a la textura propia del soporte original de piedra, teniendo en cuenta que dicho temple está aplicado en forma de capa fina, sobre a su vez, una capa muy delgada y pobre de enlucido, y en su mayoría directamente sobre la piedra. Esta capa presentaba un estado de conservación estable, exceptuando la zona superior del lateral derecho, donde mostraba un estado de pulverulencia y degradación muy avanzado e inestable, así como también en la zona del abocinamiento de la ventana, con la consiguiente pérdida de información iconográfica original que complementaría el resto del conjunto [figura 8.].
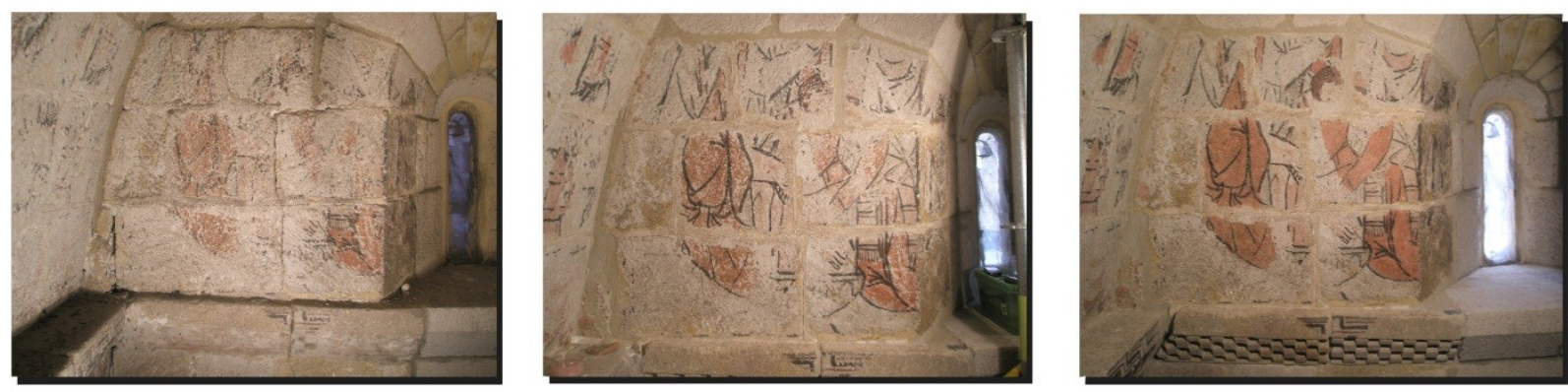

Figura 8. Lavatorio de los pies. Proceso de trabajo (Ágora).

Por lo que se refiere a la imposta que separa los dos ámbitos pictóricos ya diferenciados, está compuesta por un friso polícromo con una greca lineal entrelazada y un cuerpo ajedrezado presentando las mismas capas y características que el resto del conjunto, exceptuando la zona de la ventana, en la que se aprecia una capa de mortero de cal con restos de policromía a modo de motivos florales, ejecutado con posterioridad y sobreponiéndose al original; siendo visible el primitivo en la zona de unión entre sillares.

Encontramos una importante capa de suciedad en forma de acumulación de polvo en superficie, que en algunos casos se había introducido en las hendiduras propias del soporte, como también por debajo de la capa del enlucido y de la capa pictórica en los casos que presenta problemas de descohesión del soporte y levantamientos. Igualmente, se observaron restos del encalado que cubrió las pinturas, rellenos de arcillas, así como también restos de lechada y mortero de cemento Portland extendidos en los diferentes sillares perimetrales del mural, ocasionando una desvirtualización de la lectura real de los colores, formas y figuras.

El tratamiento de conservación y restauración, se inició con la realización de una exhaustiva documentación fotográfica y gráfica, toma de muestras de distintas zonas de las pinturas, y el examen organoléptico previo a la propia intervención restauradora, para dar paso al proceso de la limpieza mecánica superficial de las policromías y posteriormente la química.

Para la limpieza mecánica, se han utilizado brochas de pelo suave y aspiración controlada para retirar las distintas acumulaciones de polvo y suciedad en forma de partículas en superficie, tanto en la cornisa como en todo el conjunto de las pinturas y paramentos contiguos a estas. 
Sergio Pérez Martín, Marco Antonio Martín Bailón y Luciana Macedo Coelho

Recomponiendo un puzle. Disquisiciones acerca de la restauración e interpretación de unas pinturas murales de estilo gótico lineal en la iglesia de Santa María la Nueva de Zamora

Para poder proteger las zonas con alto riesgo de inestabilidad por su mal estado de conservación, antes de realizar una fijación y consolidación, se realizaron catas de limpieza de la capa pictórica y suciedad para poder definir el proceso a seguir en su fijación-consolidación según su necesidad. De acuerdo con los resultados obtenidos y las conclusiones extraídas de las distintas catas se ha optado por realizar de forma puntual una fijación de la capa pictórica y consolidación de los morteros originales (en algunos casos por inyección) en una dilución no superior al 15\% de resina acrílica en agua de cal -Primal® AC-235 (Dow Chemicals).

Los morteros originales que presentaban problemas de estabilidad y de descohesión con el soporte se han consolidado por medio de inyección de mortero PLM-AL® (Calcio hidrato, R\&C Scientifica) a distintas densidades en agua desionizada, rellenando las oquedades que pudiese haber entre ambas superficies.

A continuación se prosiguió con la retirada de los restos de encalados, adobes, así como las lechadas de mortero de cemento Portland que cubrían la policromía, eliminándose de forma mecánica a punta de bisturí y escalpelos [figura 9]. Puntualmente se han humedecido con hisopos algunas zonas con Etanol en agua desionizada en dilución 1:1 para facilitar su retirada contando en todo momento con la ayuda de unas lupas de aumento (OptiVISOR® Optical Glass Binocular Magnifier DA-5, 2,5X, Donegan Optical Company). Este proceso se efectuó con sumo cuidado sobretodo en las zonas que presentaban patologías de descohesión, falta de adhesión con el soporte o bien con problemas de levantamientos de la capa pictórica muy proclives al desprendimiento. En los casos de extremo riesgo de pérdida de policromía y con anterioridad a la limpieza mecánica se ha procedido a una fijación puntual con resina acrílica ya mencionada protegiendo la zona con grapas de papel Japón, intercalando estos dos procesos (limpieza mecánica y la fijación) según las necesidades específicas de cada zona.
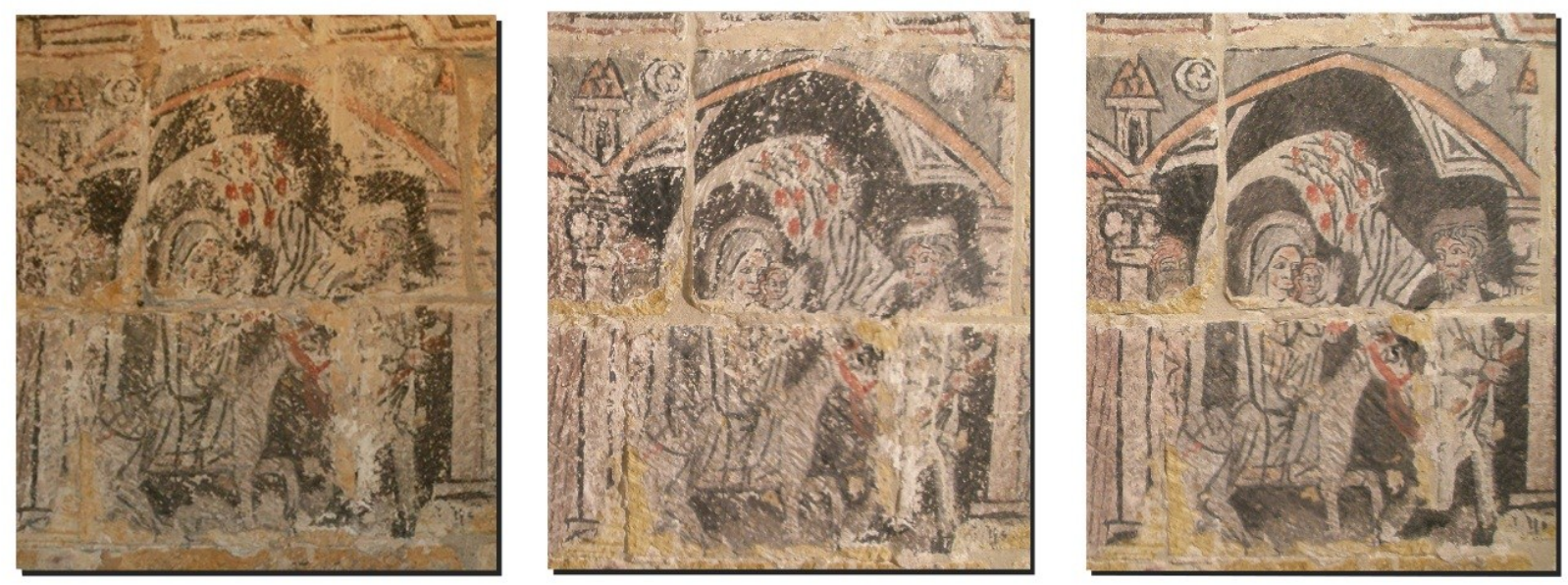

Figura 9. Huída a Egipto. Proceso de trabajo (APCZR y Ágora).

Por lo que se refiere a los elementos ajenos a la obra original, como en el caso de los cementos de Portland utilizados en los rejuntados, se han retirado en aquellas zonas próximas a los sillares con policromía. De este modo se ha recuperado el perímetro de las pinturas y se han limpiado las juntas internas afectadas con micro-cinceles, escarpas pequeñas y martillo. Al retirar el rejuntado de cemento en el lateral izquierdo del conjunto aparecieron restos de policromía original, determinando que los primeros sillares de los distintos niveles tienen continuidad hacia el interior del muro perpendicular al norte, en su lateral izquierdo, deduciendo que dicho muro se sobrepone al muro original y que ha sido ejecutado con posterioridad al de las pinturas.

De acuerdo con los resultados obtenidos y las conclusiones extraídas de las distintas catas para la limpieza se ha optado hacer una limpieza química por migración con una dilución de etanol en agua desionizada 
(1:1), con hisopos de algodón, consiguiendo devolver y recuperar la legibilidad de las escenas representadas, como también, su aspecto cromático original.

Con anterioridad a la intervención de sellado de las juntas se ha realizado la fijación de la capa pictórica con una dilución no superior al $15 \%$ de resina acrílica en agua de cal -Primal ${ }^{\circledR}$ AC-235 y papel Japón para protegerla. Las juntas saneadas se han rejuntado con mortero de cal aérea más árido (arena fina lavada y polvo de mármol 0'0-0'6 Aymar Micromar) a proporciones de 1:3, entintada con pigmentos naturales con la intención de homogeneizar las nuevas reintegraciones con el tono de los rejuntados de cal originales, imitando su textura y ligeramente por debajo de nivel del soporte-capa pictórica original. En los casos de juntas en que nos encontrábamos dos sillares de piedra ligeramente desnivelados, el criterio a seguir fue reintegrar por el nivel del sillar más bajo. Para rejuntar se han usado básicamente dos tipos de pastas de mortero de cal aérea pigmentado. Un primer mortero para la capa de arriccio con arena fina lavada a 1:3 y para el intonacco (enlucido) mezclando dos tipos de árido: arena fina lavada y polvo de mármol a proporción 1:2 más pigmento. En el caso de los agujeros se han rejuntado con mortero de cal aérea y árido, el mismo que se ha utilizado en capas de arriccio imitando la textura de la zona a tratar y llegando, en estos casos, al nivel del soporte-capa pictórica.

En los perfiles de los morteros de rejuntado original, lagunas y capas que presentaban problemas y riesgo de inestabilidad, se ha efectuado un sellado de contorno siguiendo la técnica de biselado y reforzando así las distintas capas, con el mortero de cal utilizado para las reintegraciones de enlucido de las juntas y en casos puntuales solamente con cal entintada con un poco de polvo de mármol.

Por lo que a la reintegración cromática se refiere hemos seguido el criterio de la mínima intervención propiciando la fácil identificación de las reintegraciones usando un tono por debajo de la tonalidad de la policromía original [figura 10]. La técnica pictórica elegida, y de acuerdo con la dirección facultativa, es la acuarela, siguiendo el criterio de tintas neutras y planas con carácter ilusionista. Una vez terminada la reintegración cromática se ha aplicado con pistola aerográfica una resina acrílica Paraloid® B-72 (Rohm \& Haas) a 2,5gr/litro en Acetona como capa de protección final a todo el conjunto pictórico.
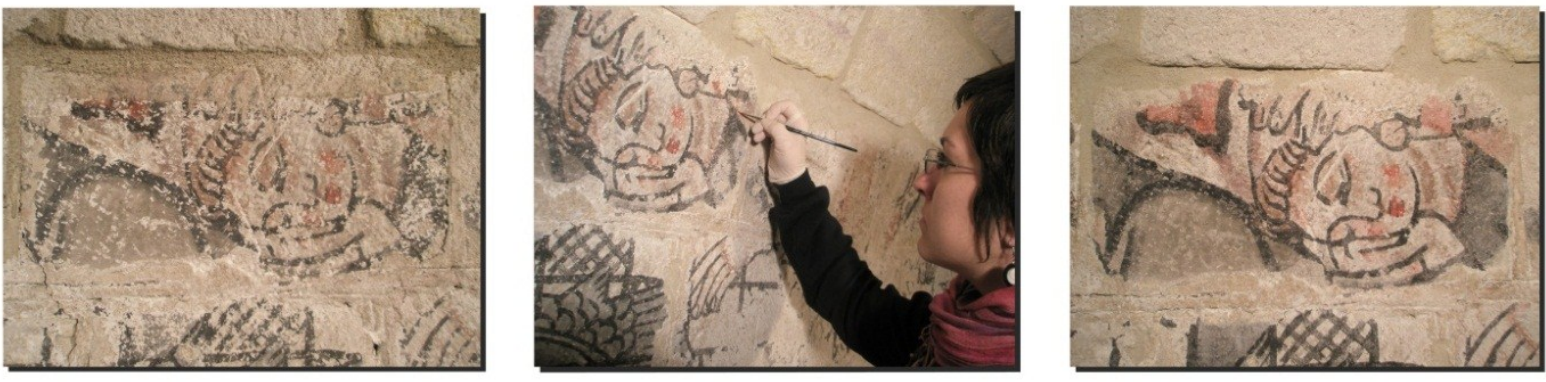

Figura 10. San Juan Evangelista. Detalle Última Cena. Proceso de trabajo (Ágora).

Como conclusión hay que destacar que el objetivo de esta intervención, con carácter de conservación y restauración, era el enfatizar la puesta de valor de la obra y facilitar la lectura de la misma. A medida que se iba avanzando en el proceso de restauración se iba generando un diálogo entre la pintura y el equipo, en este caso enriquecido por su carácter multidisciplinar, abriéndonos un amplio abanico de incógnitas y que paulatinamente, la misma pintura nos desmenuzaba nuevas referencias iconográficas e históricas hasta el momento desconocidas, o en su defecto, no documentadas ni confirmadas. Nos encontramos con ese "diálogo" en el caso de la continuidad del muro policromado norte actualmente tabicado por un muro posterior, y probablemente con la finalidad de reducir o cerrar el espacio de la Capilla, o la escena del Martirio de San Zacarías inicialmente muy encalada y situada en la parte inferior de la imposta, o el caso más sorprendente, que tiene lugar en el lateral derecho del conjunto de las pinturas, de la zona del abocinamiento de la ventana, que se ha podido determinar y recuperar la iconografía, como el Lavatorio de los pies, de los restos pictóricos inicialmente no legibles. 
Sergio Pérez Martín, Marco Antonio Martín Bailón y Luciana Macedo Coelho

Recomponiendo un puzle. Disquisiciones acerca de la restauración e interpretación de unas pinturas murales de estilo gótico lineal en la iglesia de Santa María la Nueva de Zamora

Para finalizar las tareas de restauración se ha realizado un estudio del sistema de iluminación con la intención de encontrar el método más respetuoso con la pintura llegando a la conclusión que el más idóneo seria la colocación de una iluminación controlada por sensores de movimiento para reducir el tiempo de exposición lumínica del conjunto. Y a su vez, poder ofrecer a los visitantes y al propio público zamorano la posibilidad de disfrutar de una buena percepción visual del conjunto, y lograr al igual que nosotros, ese efímero y sublime "diálogo" al redescubrir la riqueza histórica e iconográfica que les aguarda ante, sin duda, uno de conjuntos pictóricos más desconocidos de la ciudad.

\section{Notas}

[*] Este trabajo se inserta dentro del Proyecto Cultural Zamora Románica, un plan de restauración, conservación, difusión y divulgación del Románico de la ciudad de Zamora que se desarrolla entre los años 2008 y 2012. La Consejería de Cultura y Turismo de la Junta de Castilla y León promueve y financia este proyecto, en colaboración con el Ayuntamiento y Obispado de Zamora y a través de la Fundación Rei Afonso Henriques. Componen el equipo de trabajo los arquitectos Fernando Pérez (director), Marco A. Martín y Mariola Santos; los arquitectos técnicos Pedro Andrés y Marisa Silva; y el historiador Sergio Pérez. Más información en www.zamoraromanica.es.

En este caso la redacción del proyecto de restauración y posterior dirección facultativa corrió a cargo de la restauradora Ana Prieto y el seguimiento fotográfico por Javier Lucas. Toda la documentación se encuentra depositada en el Archivo del Proyecto Cultural Zamora Románica, en adelante (APCZR).

[**] La dirección de obra corrió a cargo de Ferrán Máuriz. Integraron el equipo de conservación-restauración en sus distintas fases: Luciana Macedo, Antonio Martín, Elena Urueña, Yanira Carrera y F. Javier Reyes.

[1] Para una aproximación reciente a esta metodología de trabajo, véase Pérez Martín y Martín Bailón (2010).

[2] En la primera edición de la guía realizada en 1958 y publicada dos años más tarde aún no aparecían recogidas los ciclos pictóricos de la iglesia.

[3] Consúltese al respecto los trabajos de Heras Hernández (1973: 262) o Ramos de Castro (1977: 198-202 y 429).

[4] De manera coetánea se editaba una guía de los templos capitalinos de Rivera de las Heras (2001: 149) que en el capítulo dedicado a Santa María la Nueva reconocía correctamente, por primera vez, seis de las diez escenas que componen el mural.

[5] Guadalupe Ramos (1977: 429) señala que a su parecer las pinturas habrían sido retocadas.

[6] Durante el llamado Motín de la Trucha, la iglesia fue incendiada por el pueblo llano amotinado cuando los nobles de la ciudad se encontraban reunidos en su interior. Éstos discutían qué castigo infligir al hijo de un zapatero que se había opuesto a los abusos con que los aristócratas disfrutaban de sus privilegios en la compra de víveres. En este incendio debió destruirse gran parte de la iglesia, que hubo de reconstruir el pueblo para recibir el perdón real y la absolución papal.

[7] Con la redacción del "Proyecto de conservación y restauración. Restos de armadura policromada" por Iván J. López, y tras su inminente intervención, se procederá a la puesta en valor de las mismas en la propia iglesia donde fueron recuperadas (APCZR., Proyecto básico y de ejecución. Intervención en cubiertas y ábside. Iglesia de Santa María la Nueva. Agosto 2009).

[8] AGA., (3)115 26/00295, agosto 1949. Proyecto de restauración del ábside del siglo XII en la iglesia de Santa María la Nueva. Arquitectos: L. M. Pidal / J. Pons Sorolla; AGA., (3)115 26/00295, enero 1951. Proyecto de obras de restauración en la iglesia de Santa María la Nueva; AGA., (3)115 26/00295, septiembre 1953. Proyecto de obras de restauración de cubiertas en la iglesia de Santa María la Nueva; AGA., (3)115 26/00310, julio 1957. Proyecto de obras de recalzo de sillería en la iglesia de Santa María la Nueva y AGA., (3)115 26/00161, marzo 1958. Proyecto de obras de pavimentación en la iglesia de Santa María la Nueva. 
Sergio Pérez Martín, Marco Antonio Martín Bailón y Luciana Macedo Coelho

Recomponiendo un puzle. Disquisiciones acerca de la restauración e interpretación de unas pinturas murales de estilo gótico lineal en la iglesia de Santa María la Nueva de Zamora

[9] La memoria histórica sobre el edificio repetida en todos los proyectos es copia idéntica de la que publicara Gómez Moreno en su Catálogo Monumental treinta años atrás. Esto podría haber sido válido para el primer proyecto, pero no así para los siguientes, una vez desmontado el camarín y sobre todo una vez descubiertas las pinturas. Del mismo modo la planimetría es muy interesante pues es el primer levantamiento de la iglesia riguroso que conocemos, pero nos crea dudas en cuanto al estado inicial y final de cada proyecto. Quizás lo más detallado y preciso sean la mediciones del presupuesto, aunque sabemos que no tienen por qué coincidir necesariamente con la obra realmente ejecutada.

[10] En la memoria de intervención del proyecto de 1951 aparece: "...se incluye una partida para limpieza, desencalado y rejuntado de los muros interiores de la iglesia. Esta operación habrá de realizarse con toda la precaución y mediante cuidadosas operaciones por personal especializado ya que en varios puntos de los viejos muros aparecen pinturas que interesa delimitar y restaurar en fase posterior.". Y en el pliego de condiciones especifica: "Es de especial importancia la cuidada ejecución de la limpieza y desencalado de muros que se llevará a cabo por personal especializado." “...en zonas molduradas solo podrán aplicarse lavados sucesivos y en los puntos en que aparezcan pinturas, el tipo de estas indicarán la técnica especial a seguir".

[11] Sobre el tema y la iconografía de las parteras y la Natividad véase el interesante trabajo de Morente Parra (2009). Existe disparidad de interpretaciones en los textos apócrifos, donde se habla indistintamente de una o dos parteras, en ocasiones aparecen sus nombres, que también difieren según el relato, etc. Un estudio de necesaria consulta fue el realizado por Réau (1996: 230-233), si bien, la lectura de algunas de las fuentes resulta de sumo interés (Ps. Mt. XIII, 3-5 y Pr. Ia. XIX-XX).

[12] Entre ellos en el Homiliario de San Gregorio Nacianceno del siglo IX, en un fresco en Gratchanitsa (Serbia) fechado en 1320 (Réau 1996: 281), o en las pinturas de la iglesia rupestre de San Eustacio en la Capadocia, una obra del siglo X (Santos Otero 2005: 354).

[13] Por evidentes razones de espacio no podemos extendernos en el interesante análisis de estas fuentes y su repercusión en la iconografía, sin embargo si podemos emplazar a los trabajos de Hernández Fernández (2006) y Vergara Jiménez y Fraile Gil (1984).

\section{Bibliografía}

GARCÍA DE PRUNEDA, S. (1907). "Santa María la Nueva de Zamora (Bosquejo histórico-artístico)", en Boletín de la Sociedad Castellana de Excursiones, III, 53: 101-111.

GRAU LOBO, L. (2001). Pintura murales de la Edad Media en la provincia de Zamora. Zamora.

GUTIERREZ BAÑOS, Fernando. (2005). Aportación al estudio de la pintura de estilo gótico lineal en Castilla y León precisiones cronológicas y corpus de pintura mural y sobre tabla. Madrid: Fundación Universitaria Española.

HERAS HERNÁNDEZ, D. (1973). Catálogo artístico-monumental y arqueológico de la diócesis de Zamora, Zamora.

HERNÁNDEZ FERNÁNDEZ, A. (2006). "El milagro del trigo: de los evangelios apócrifos al folklore y la literatura”. En Culturas Populares. Revista Electrónica, 3, 1-16.

MORENTE PARRA, Ma . I. (2009). "Espacios de ámbito femenino: las parteras en la Navidad". En La Natividad: arte, religiosidad y tradiciones populares, Campos y Fernández de Sevilla, F. J. (coord.). Madrid, 813-827.

NAVARRO TALEGÓN, J. (1988). "Pintura Medieval”. En Zamora en la Edad Media, Navarro, J. (coord..). Zamora, $36-44$.

NUÑO GONZÁLEZ, J. (2002). "Iglesia de Santa María la Nueva”. En Enciclopedia del Románico en Castilla y León. Zamora, García Guinea, M.A. y Pérez González, J. Ma (dir.). Aguilar de Campoo, 411-425.

PÉREZ MARTIN, S. y MARTÍN BAILÓN, M. A. (2010). "Releyendo el románico de Zamora. Experiencias y encuentros del Proyecto Cultural Zamora Románica”, Románico, 11: 42-51. 
Sergio Pérez Martín, Marco Antonio Martín Bailón y Luciana Macedo Coelho

Recomponiendo un puzle. Disquisiciones acerca de la restauración e interpretación de unas pinturas murales de estilo gótico lineal en la iglesia de Santa María la Nueva de Zamora

RAMOS DE CASTRO, G. (1977). El arte románico en la provincia de Zamora. Zamora.

RÉAU, L. (1996). Iconografía del arte cristiano. Iconografía de la Biblia. Nuevo Testamento, t. 1, vol. 2. Barcelona: El Serbal.

RIVERA DE LAS HERAS, J. Á. (2001). Por la Catedral, iglesias y ermitas de la ciudad de Zamora. León: Edilesa.

SANTOS OTERO, A. de. (2005). Los Evangelios Apócrifos. Madrid: Biblioteca de Autores Cristianos.

VELASCO RODRÍGUEZ, V. (1960). Guía turistica de la provincia de Zamora, $1^{\text {a }}$ ed. Zamora: Cámara Oficial de Comercio e Industria de Zamora.

VELASCO RODRÍGUEZ, V. (1962). Guía turística de la provincia de Zamora, 2ª ed. Zamora: Rústica Editorial ilustrada.

VERGARA JÍMENEZ, F., FRAILE GIL, J. M. (1984). “El milagro del Trigo, un tema apócrifo”. En Revista de Folklore, 04b, 44, 45: 52.

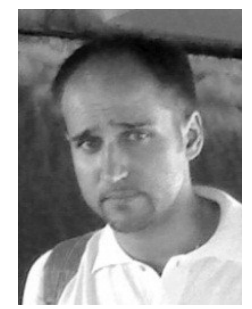

\section{Sergio Pérez Martín}

sergioperez@zamoraromanica.es

Doctorando en Historia del Arte por la Universidad de Valladolid y especialista en Evaluación y Gestión de Patrimonio Histórico-Artístico por la de Salamanca. Ha trabajado y colaborado en la investigación, catalogación y gestión del patrimonio castellanoleonés en instituciones como la Fundación Siglo, la Junta de Castilla y León, las Fundaciones de Las Edades del Hombre y del Patrimonio Histórico de Castilla y León o la Fundación Santa María la Real. En la actualidad es el historiador del Proyecto Cultural Zamora Románica, profesor del Máster en Arte Sacro y Patrimonio Cultural de la Iglesia de la Universidad Pontificia de Salamanca y miembro de varios equipos universitarios de investigación.

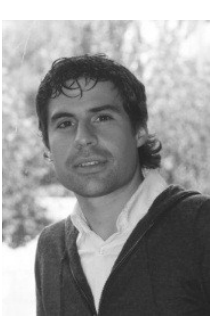

\section{Marco Antonio Martín Bailón}

marcomartin@zamoraromanica.es

Arquitecto por la Universidad de Valladolid. Desde 2008 es miembro activo del Proyecto Cultural Zamora Románica. Becado por la Fundación Caja de Arquitectos en 2005-07 colabora en el Estudio de D. Manuel Gallego Jorreto en Galicia. Participa en investigaciones y exposiciones en el ámbito de la arquitectura, el arte y el pensamiento (declaración BIC iglesia Pumarejo de Tera de Miguel Fisac, Zamora 2009; Foro Arquia Próxima, Valencia 2008; Exposición Plomadas, colección Primitivo González, Zamora 2007 y Barcelona 2008).

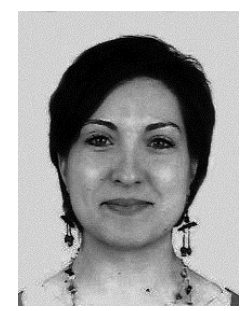

\section{Luciana Macedo Coelho}

lucimacoelho@yahoo.es

Licenciada en Bellas Artes con especialidad en Conservación-Restauración en el año 2003. Desde entonces trabaja de forma activa en el Grup Tècnic, Asociación profesional de conservadores y restauradores de Bienes culturales de Cataluña. Paralelamente ha trabajado en diferentes empresas de restauración, desarrollando especialidades tales como pintura mural, materiales pétreos, policromía sobre madera y el órgano de la Basílica de Santa María de Castelló d'Empúries. En los últimos años su actividad profesional se ha centrado principalmente en la restauración de edificios históricos catalogados y en particular en los estucos de cal, esgrafiados y estucos al fuego. En la actualidad trabaja como jefa de equipo en el proyecto de restauración del interior de la Catedral de Tarragona. 